\title{
Cross-Sectional Transmission Electron Microscopy Sample Preparation of Soldering Joint Using Ultramicrotomy
}

\author{
Jee-Hwan Bae, Ye-Na Kwon, Cheol-Woong Yang* \\ School of Advanced Materials Science and Engineering, Sungkyunkwan University, Suwon 16419, Korea
}

\author{
*Correspondence to: \\ Yang CW, \\ Tel: +82-31-290-7362 \\ Fax: +82-31-290-7371 \\ E-mail: cwyang@skku.edu \\ Received September 26, 2016 \\ Revised September 26, 2016 \\ Accepted September 26, 2016
}

\begin{abstract}
Solder/electroless nickel immersion gold (ENIG) joint sample which is comprised of dissimilar materials with different mechanical properties has limited the level of success in preparing thin samples for transmission electron microscopy (TEM). This short technical note reports the operation parameters for ultramicrotomy of solder joint sample and TEM analysis results. The solder joint sample was successfully sliced to $50 \sim 70 \mathrm{~nm}$ thick lamellae at slicing speed of $0.8 \sim 1.2 \mathrm{~mm} / \mathrm{s}$ using a boat-type $45^{\circ}$ diamond knife. Ultramicrotomy can be applied as a routine sample preparation technique for TEM analysis of solder joints.
\end{abstract}

Key Words: Sn-Ag solder, Electroless nickel immersion gold plating, Interfacial reaction layer, Ultramicrotomy, Transmission electron microscopy

\section{INTRODUCTION}

Many studies have reported the interfacial reaction of Sn- $\mathrm{Ag} /$ electroless nickel immersion gold (ENIG). Various analysis techniques, such as scanning electron microscopy, electron probe microanalyzer, and transmission electron microscopy (TEM), have been used to examine interfacial reaction. Among them, TEM equipped with analytical attachments offers the most complete tool for characterizing the formation of intermetallic compounds (IMCs) at the interface. However, solders are typically soft and ductile, while IMCs tend to be quite hard and brittle, which has limited the level of success in preparing TEM samples.

We utilized ultramicrotomy since it might offer a reasonable and relatively quick alternative in this case. Ultramicrotomy has been used for the preparation of TEM specimens from biological materials and extending a range of materials including polymers, coating layer, particles, and even metals (Becker \& Bange, 1993; Glanvill, 1995; Howell et al., 1995). TEM sample making to section hard materials by ultramicrotomy are not new. Besides, it has been traditionally considered that the mechanical damage during sectioning by diamond knife might hinder unambiguous specimen characterization. However, this technique also has many advantages such as no ion beam irradiation damage, no chemical mixing, no differential thinning rate and the ease of preparation of many serial sections with large, thin areas of uniform thickness in a relatively short time (Quintana, 1997). The increasing acceptability of ultramicrotomy in materials science is evidenced by a number of recent paper giving results for different hard materials (Hwang \& Suganuma, 2003).

\section{MATERIALS AND METHODS}

The solder joint sample was prepared using conventional Sn3.5wt.\%Ag solder and Cu plate with ENIG surface finish. The solder balls were bonded to the ENIG substrate in a reflow process using rosin mildly activated (RMA) flux in a reflow machine (RF-430-N2; Japan Pulse Laboratory Co., Ltd., Japan) with a maximum temperature of $255^{\circ} \mathrm{C}$ for 1 minute. TEM cross-sectional sample was prepared by ultramicrotomy (MT 7000; RMC Boeckeler, USA). The solder joint sample was fixed directly to the 'Flat Specimen Clamp' without embedding in epoxy resin (Fig. 1). The trimming process to provide a suitable cutting area was carried out slowly and very

(a) This is an open-access article distributed under the terms of the Creative Commons Attribution Non-Commercial License (http://creativecommons.org/licenses/by-nc/4.0) which permits unrestricted noncommercial use, distribution, and reproduction in any medium, provided the original work is properly cited.

Copyrights () 2016 by Korean Society of Microscopy 
carefully because the glass knife for trimming was broken repeatedly due to a high hardness of solder joint sample. After trimming process, the sample was cut into $50 \sim 70 \mathrm{~nm}$ thick slices with $0.8 \sim 1.2 \mathrm{~mm} / \mathrm{s}$ slicing speed using a boat-type $45^{\circ}$ diamond knife (Drukker International, The Netherlands) filled with distilled water. The sections floating on the distilled water surface were collected onto 200 mesh copper grid. The microstructure and chemical composition were observed by TEM (JEM-2100F; JEOL Co., Ltd., Japan) equipped with energy dispersive $\mathrm{X}$-ray spectrometer (EDS).

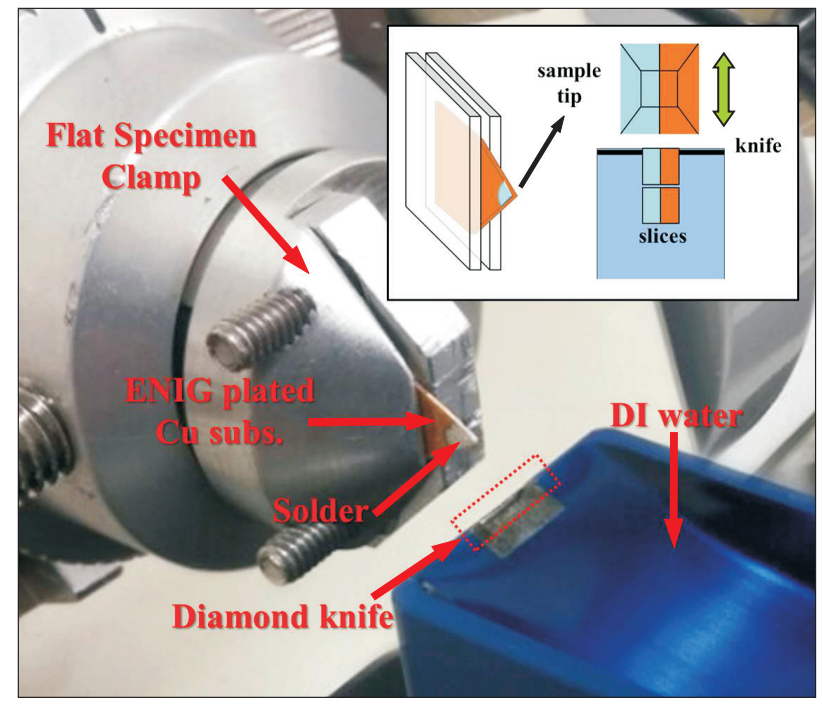

Fig. 1. Sample holder of ultramicrotome. The solder joint sample was fixed directly to the 'Flat Specimen Clamp' without embedding in epoxy resin. The interface of solder/ENIG plated substrate was aligned perpendicular to the diamond knife edge.

\section{RESULTS AND DISCUSSION}

Fig. 2 shows a typical low magnification TEM micrograph of as-sectioned slices from $\mathrm{Sn}-3.5 \mathrm{Ag} / \mathrm{ENIG}$ joint sample prepared by ultramicrotomy technique. These slices tended to crack and bend during sectioning but this did not become a problem in characterization such as size measurement, and determination of crystal structure, crystallinity and chemical composition. The observing area was as large as a few tens of micrometers.

Fig. 3 shows a high magnification TEM micrograph of a sectioned slice and the nano-beam electron diffraction (NBED) patterns obtained from interfacial reaction layers. Based on the TEM image contrast, it was apparent that the interfacial reaction layers between a predominant phase
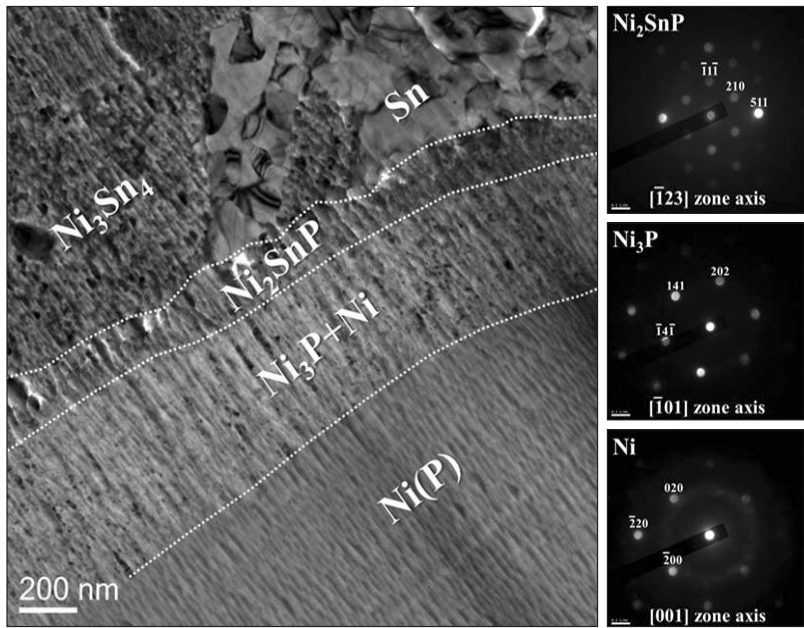

Fig. 3. High magnification TEM micrograph of a sectioned slice and NBED patterns obtained from interfacial reaction layers. Although there was wrinkling, ultramicrotomy provides contamination free sections with large, thin area of uniform thickness, which is suitable for the TEM study using electron diffraction and $\mathrm{X}$-ray microanalysis.


Fig. 2. Low magnification TEM micrographs of as-sectioned slices from $\mathrm{Sn}$ $3.5 \mathrm{Ag} / \mathrm{ENIG}$ joint sample prepared by ultramicrotomy technique. The sections were collected onto 200 mesh copper grid. The observing area was as large as a few tens of micrometers. 
of $\mathrm{Ni}_{3} \mathrm{Sn}_{4}$ IMC and the electroless $\mathrm{Ni}(\mathrm{P})$ substrate were composed of two more reaction layers rather than one. The lower layer next to the electroless $\mathrm{Ni}(\mathrm{P})$ exhibited a light gray contrast with black spots, while the upper layer next to the $\mathrm{Ni}_{3} \mathrm{Sn}_{4}$ IMC showed a dappled-gray contrast. Although there was wrinkling in the sections due to the mechanical stress during sectioning by diamond knife, it did not affect the TEM study using electron diffraction and X-ray microanalysis. Identification of phases formed was performed by using NBED and EDS analysis. Diffraction pattern indexing confirmed each layer which was distinguished by the difference in TEM image contrast: the $\mathrm{Ni}_{3} \mathrm{Sn}_{4}$ IMC layer, $\mathrm{Ni}_{2} \mathrm{SnP}$ layer, and final layer composed of $\mathrm{Ni}_{3} \mathrm{P}$ and $\mathrm{Ni}$ nano-crystallites. Detailed TEM analysis results of $\mathrm{Sn}-\mathrm{Ag} /$ ENIG solder joint sample prepared by ultramicrotomy were reported elsewhere (Kang et al., 2008, 2011).

\section{CONCLUSIONS}

In summary, ultramicrotomy technique is suitable to prepare thin sections of Sn-Ag solder/ENIG joint samples.
Even though there is a risk of breaking diamond knife during sample preparation due to the high hardness of metal component in the sample, ultramicrotomy enables the relatively rapid preparation of thin sectioned slices for the TEM analysis. In addition, this technique provides contamination free sections with large, thin areas of uniform thickness.

\section{CONFLICT OF INTEREST}

No potential conflict of interest relevant to this article was reported.

\section{ACKNOWLEDGMENTS}

This work was partially supported by NRF grants by the Korean government (MSIP and MOE) (NRF-2011-0030058 and NRF-2015R1D1A1A01059653), and in part by the National Research Council of Science \& Technology (NST) grant by the Korea government (MSIP) (No. CRC-15-06-KIGAM).

\section{REFERENCES}

Becker O and Bange K (1993) Ultramicrotomy: an alternative cross sections preparation for oxidic thin films on glass. Ultramicroscopy 52, 73-84.

Glanvill S R (1995) Ultramicrotomy of semiconductors and related materials. Microsc. Res. Tech. 31, 275-284.

Howell D A, Heckman J R, and Crimp M A (1995) Preparation of metal multilayer TEM cross-section using ultramicrotomy. J. Microsc. 180, 182-185.

Hwang C W and Suganuma K (2003) Interface microstructures between Ni-P plating and Sn-Ag-(Cu) lead-free solders. J. Mater. Res. 18,

\section{0-2543.}

Kang H B, Lee J W, Bae J H, Park M H, Yoon J W, Jung S B, Ju J S, and Yang C W (2008) Initial interfacial reaction layers formed in Sn-3.5Ag solder/electroless Ni-P plated Cu substrate system. J. Mater. Res. 23, 2195-2201.

Kang H B, Bae J H, Yoon J W, Jung S B, Park J, and Yang C W (2011) Microstructure of interfacial reaction layer in Sn-Ag-Cu/electroless $\mathrm{Ni}$ (P) solder joint. J. Mater. Sci.: Mater. Electron. 22, 1308-1312.

Quintana C (1997) Ultramicrotomy for cross-sections of nanostructure. Micron 28, 217-219. 